\title{
Urgences
}

\section{ceux mobilisent l' (fragments)}

\section{Joseph Guglielmi}

Numéro 33, octobre 1991

Poésies parallèles : France - Québec

URI : https://id.erudit.org/iderudit/025659ar

DOI : https://doi.org/10.7202/025659ar

Aller au sommaire du numéro

Éditeur(s)

Urgences

ISSN

0226-9554 (imprimé)

1927-3924 (numérique)

Découvrir la revue

Citer ce document

Guglielmi, J. (1991). ceux mobilisent l' (fragments). Urgences, (33).

https://doi.org/10.7202/025659ar d'utilisation que vous pouvez consulter en ligne.

https://apropos.erudit.org/fr/usagers/politique-dutilisation/ 
Joseph Guglielmi

André Gervais 


\section{ceux mobilisent l' (fragments)}

Joseph Guglielmi

voir de figure en figure from whom phantom walk together :

L'

le premier qui trouva l'art

origine

comme

de la boue solaire.

Quelle que soit la figure, sans même vie

ni le fantôme

habitante,

arrache

lignes de vie...

Se pose sur la figure avec terreur intérieure

et de ses lèvres.

resucée du bond roux

Avec des cris, des raptus

arrache

l'herbe fétiche comme détache sa tombe, le masque prémonition, phantom répète together. Force git dans l'obsession. Chat brun fend la chose ouverte

à tous les songes

est mourante!

demandait si j'étais morte...

Quel mystère les lisant:

Cheveux de pierre

* souvenir d'un lourd baiser *

et bande.

Ciel de proie et sa salive, panse collée

sous-terraine;

poésie n'est pas le coup de dés mais le dé lui

dado

seul

dador Lezama

Poisson aveugle du sexe

and distillation hybris. odeur de poisson assise, cal 
donne

cul par cinq de la main

le tremble

l'écrou et traduire, accuse plaisir, soleil, mimesis et tout Puis, ramone son barroco le geste dansé des lèvres

ou rictus du dernier acte,

na

c'est perdu ou périr, mange la syllabe reine.

Olson

disait * dogmatic *

descendre au fond de la gorge

à

la place où naît le souffle...

Rien n'est nécessaire

ni emblème ni maison réelle,

seul le souffle, une danse invisible entre

ou esprit, mots qui tombent comme des pierres.

morceaux de langue

Écrire, peser la mort et les restes de pensée, faux

christs

aux couilles d'ivoire à la mémoire gelée

enfant

et

la terreur...

Apparition apollon ouvre la pulpe silence; imagination maison lévite

à côté du fleuve.

Appogiattura

sur l'image dépeinte, le ventre nu comme un ventre poisson noyé dans la boue

Sortie du rêve, la main écarte les lèvres

Pointe

fouille.

que l'ange faseille « tourne la main d'une étoile * Une panse offerte au palpe (de José Lezama Lima) Sa grenouille

in nuit farcie 
22

Toile

éteinte, esquintée à domicile

suspension quiète

\section{du vers un pas}

de l'intellect ou de messe, kifkif

La vamp

$$
\text { ire brû }
$$

lante de sa chair vidée, galop enfoncé profond et Dadim fleur au rouge ardent sous la main de ton derviche cœur à vif au bout des doigts

à lui

dormant sur le mythe

« faisant fleur * d'un trait de chair, humide poisson de langue et du miroir resti

Ciseau à travers le tué par le sexe, songe 